\title{
Research on the Copyright of User Content in Online Education Platform
}

\author{
Minmin Zhang \\ School of Public Affairs,University of Science and Technology of China,96 Jingzhai Street, \\ Hefei 230026, China
}

\begin{abstract}
Online interaction plays an important role in online education. At the same time, it also creates a series of copyright issues. How to establish the copyright of the "user content" submitted by the user during the online interaction session, and how the platform and the user negotiate the distribution of rights and interests are all urgently resolved. This paper selects 20 online education platform's terms of use and privacy policy for research, and concludes that foreign platform have generally signed relevant agreements with users to stipulate the ownership of user content copyrights, while domestic users and platform do not attach importance to the issue of user content copyrights; the relevant agreements for user's content copyrights are detrimental to users,no matter types of contracts, distribution of copyrights or division of responsibilities . In this regard, we should use legal to regulate Agreement content and signing behavior which provided by online education platforms, protect the user's rights, which has great significance in promoting the development of online education.
\end{abstract}

Keywords:online education, copyright, user, terms of use

DOI: $10.7176 / \mathrm{JEP} / 10-18-09$

Publication date: June $30^{\text {th }} 2019$

\section{Introduction}

Online education is a network-based approach to teaching. The rapid development of information technology has created a learning style across time and space, which has fundamentally changed the learning way. Khan Academy has created a "teaching myth" that recruits a teacher and a computer to attract tens of millions of students. It has set off a wave of online education in the education sector. With its characteristics and advantages, online education is getting bigger . People's recognition, various emerging online schools and related websites have sprung up. According to statistics, the online education market in China reached 280 billion yuan in 2017. It is expected that the market size will exceed 300 billion in 2018.

The way of online learning has gradually deepened, and the continuous upgrade of online education technology and increasingly rich and mature online learning products will further expand the online education market. In order to increase the attractiveness of online education, to ensure that students are more focused on online learning, and to improve the security of online education, the interaction of online education has been paid more and more attention. At the same time, the problem that how to deal with user content generated by online education interaction has to be faced. User content refers to the works created by the online education platform users in the original, change, compilation, translation and other forms of the course services provided by the platform, and uploaded to the platform through their personal network user accounts, including the user submitted during the learning process. Online coursework and participating online discussions, including user content that is innovative, novel, and theoretical. In accordance with the relevant provisions of the Copyright Law, such user content is protected by the Copyright Law, and the user enjoys the copyright of this part of the User Content in accordance with the general provisions of the copyright owner ${ }^{[1]}$. However, in the actual operation process, in order to avoid risks, strive for and protect their own interests, online education platform service providers often use their dominant position, sign unequal agreements with users, and unequal licenses in terms of use and privacy policies ${ }^{[2]}$. And the disclaimer, depriving the user of the rights to the user's content.

At present, the research on the copyright of online education mainly focuses on the analysis of copyright ownership and the issue of copyright system. The copyright of user content in the issue of copyright ownership has not been studied in depth. The author hopes to analyze the practice of online content of online education users by analyzing the user content of the online education platform at home and abroad and the user content part of the privacy policy, in order to provide opinions and suggestions for protecting the copyright of user content and promoting the healthy development of online education.

\section{Online Education Platform User Content Agreement Overview}

\subsection{Sample selection}

"Internet Weekly" and eNet Research Institute combed and ranked the domestic online education market from iBrand (network social influence), iSite (self-network construction capability), iPower (industry status) three dimensions indicators, and regularly released on an annual basis. This ranking has a high reference value for the 
sample selection in this paper. Based on the "2016 Online Education Platform TOP100" and "2017 Online Education Company Ranking", combined with the platform's business model and service targets, Baidu Education, Hujiang Net, NetEase Cloud Classroom, Tencent Classroom, and University Education were selected. New Oriental Online, Xuesisi Network School, Huatu Network School, Cross-test Network School, School Online 10 domestic online education platforms; similarly, based on the comprehensive consideration of the platform iBrand, iSite, iPower three dimensions indicators, Udacity, Udemy, Coursera, edX, FutureLearn, Iversity, Open2Study, FUN MOOC, Novoed, Khan Academy 10 foreign online education platforms, a total of 20 most representative online education platforms, select the platform's terms of use and privacy policy as a research sample, the user content section focuses on research and comparison, analyzes the copyright issues, and provides opinions and suggestions for the improvement of online education user content agreement.

\subsection{Basic situation of online education platform}

In order to better analyze the online content of the online education platform, the online education platform selected in this paper is investigated for profit and user content generation. The results are shown in Table 1. Most foreign online education platforms do not charge for courses, but they charge fees when they take exams or issue certificates. Most domestic online education platforms use a parallel and free-to-free model to distinguish between open and premium courses, free of charge for open classes and premium courses. Different online education platforms provide different forms for users to participate in the course, mainly in the form of homework, real-time interaction, discussion area, study group, post, etc. This is also the link of user content generation in the online education platform, but due to the interaction of different platforms. Due to factors such as strength and weakness, convenience, the quantity and quality of user content vary, Generally speaking, the interaction of foreign online education platforms is high, and the interactive links of domestic online education platforms have problems such as form and poor interaction. Therefore, in comparison, the online online education platform has a large number of user content and higher quality than domestic ones.

Table 1. Basic information of online education platform

\begin{tabular}{|c|c|c|}
\hline $\begin{array}{c}\text { Online education } \\
\text { platform }\end{array}$ & Whether to profit & User content generation \\
\hline Udacity & Course fee & $\begin{array}{l}\text { Students submit assignments, study } \\
\text { groups }\end{array}$ \\
\hline Udemy & Course fees, less free & $\begin{array}{c}\text { Users develop and create their own } \\
\text { courses }\end{array}$ \\
\hline Coursera & Free but charged for certification & community \\
\hline edX & Free but charged for certification & forum \\
\hline FutureLearn & $\begin{array}{l}\text { Some courses are charged for exams or } \\
\text { certificates }\end{array}$ & Real-time interaction \\
\hline Iversity & free & forum \\
\hline Open2Study & Free but charged for certification & forum \\
\hline FUN MOOC & free & $\mathrm{N} / \mathrm{A}$ \\
\hline NovoEd & Part of the course fee & studying group \\
\hline Khan Academy & free & share it \\
\hline Baidu Education & Part of the course fee & Homework \\
\hline Hujiang Net & Course fee & interactive platform \\
\hline $\begin{array}{l}\text { Netease Cloud } \\
\text { Classroom }\end{array}$ & Partially free & forum \\
\hline Tencent classroom & Partially free & Online discussion, QQ group \\
\hline Academic education & Course fee & N/A \\
\hline New Oriental Online & Course fee & Online discussion, QQ group \\
\hline $\begin{array}{l}\text { Learn and think online } \\
\text { school }\end{array}$ & Course fee & $\begin{array}{l}\text { Real-time interaction, homework } \\
\text { composition }\end{array}$ \\
\hline Huatu Network School & Partially free & Online learning platform \\
\hline $\begin{array}{l}\text { Cross-test network } \\
\text { school }\end{array}$ & Course fee & Homework \\
\hline School online & Free, part of the charge & Post: Notes, sharing \\
\hline Netease Open Class & Free, part of the charge & Post \\
\hline
\end{tabular}

\subsection{Assignment of Rights in User Content Agreements}

As shown in Table 1, the online education platform generally requires the user to authorize the generated content to the platform or does not involve the part of the content in different forms, and the user content is specified in 
the terms of use and the privacy policy, except that FutureLearn does not have the tort liability. In addition to the agreement, the rest of the platform requires the trainees to ensure that the content is generated without rights and bear tort liability.

Table 2. Online Education Platform User Content Rights Assignment

\begin{tabular}{|c|c|c|c|}
\hline $\begin{array}{l}\text { Online education } \\
\text { platform }\end{array}$ & $\begin{array}{l}\text { Whether online content is } \\
\text { authorized to the platform }\end{array}$ & $\begin{array}{l}\text { Does the student guarantee } \\
\text { that there is no right issue }\end{array}$ & $\begin{array}{l}\text { If the infringement problem } \\
\text { occurs, the student is } \\
\text { responsible }\end{array}$ \\
\hline Udacity & $\mathrm{Y}$ & $\mathrm{Y}$ & $\mathrm{Y}$ \\
\hline Udemy & $\mathrm{Y}$ & $\mathrm{Y}$ & $\mathrm{Y}$ \\
\hline Coursera & $\mathrm{Y}$ & $\mathrm{Y}$ & $\mathrm{Y}$ \\
\hline edX & $\mathrm{Y}$ & $\mathrm{Y}$ & $\mathrm{Y}$ \\
\hline FutureLearn & $\mathrm{Y}$ & $\mathrm{Y}$ & no agreement \\
\hline Iversity & $\mathrm{Y}$ & $\mathrm{Y}$ & $\mathrm{Y}$ \\
\hline Open2Study & $\mathrm{Y}$ & $\mathrm{Y}$ & $\mathrm{Y}$ \\
\hline FUN MOOC & no agreement & no agreement & no agreement \\
\hline Novoed & $\mathrm{Y}$ & $\mathrm{Y}$ & $\mathrm{Y}$ \\
\hline Khan Academy & $\mathrm{Y}$ & $\mathrm{Y}$ & $\mathrm{Y}$ \\
\hline Baidu Education & $\mathrm{Y}$ & $\mathrm{Y}$ & $\mathrm{Y}$ \\
\hline Hujiang Net & $\mathrm{Y}$ & $\mathrm{Y}$ & $\mathrm{Y}$ \\
\hline $\begin{array}{l}\text { Netease Cloud } \\
\text { Classroom }\end{array}$ & \multicolumn{3}{|c|}{ no agreement } \\
\hline Tencent classroom & \multicolumn{3}{|c|}{ no agreement } \\
\hline $\begin{array}{l}\text { Academic } \\
\text { education }\end{array}$ & \multicolumn{3}{|c|}{ no agreement } \\
\hline $\begin{array}{c}\text { New Oriental } \\
\text { Online }\end{array}$ & \multicolumn{3}{|c|}{ no agreement } \\
\hline $\begin{array}{l}\text { Learn and think } \\
\text { online school }\end{array}$ & \multicolumn{3}{|c|}{ no agreement } \\
\hline $\begin{array}{c}\text { Huatu Network } \\
\text { School }\end{array}$ & \multicolumn{3}{|c|}{ no agreement } \\
\hline $\begin{array}{c}\begin{array}{c}\text { Cross-test network } \\
\text { school }\end{array} \\
\end{array}$ & \multicolumn{3}{|c|}{ no agreement } \\
\hline School online & \multicolumn{3}{|c|}{ no agreement } \\
\hline
\end{tabular}

Table 2 shows that the licensing methods of user content reached by the online education platform and users can be divided into several categories ${ }^{[3]}$ : (1) Uncontracted. FUN MOOC and most domestic online education platforms have not reached a relevant agreement with users on the content generated, which means, the attribution and licensing methods of user content are in an uncertain state; (2) The overlord clause type. Coursera, FutureLearn, Novoed, Baidu Education, and Hujiang.com stipulate non-exclusive, free, permanent, irrevocable licenses in the Terms of Use, such as Baidu Education:

"For users to upload any content to Baidu's website through Baidu's services (including but not limited to Post Bar, Know, Baidu Cloud, etc.), the user agrees that Baidu has free and permanent worldwide, irrevocable, non-exclusive, fully sublicensed rights and licenses to use, copy, modify, adapt, publish, translate, create derivative works, disseminate, perform, and display such content (in whole or in part), and this content is incorporated into any other form of work, media or technology currently known or later developed."

The edX, Udacity, Open2Study, and Khan Academy platforms also stipulate that commercial content can be used for user content; (3) Reasonable agreement. The Udemy and Iversity platforms only stipulate nonexclusive, non-exclusive licensing methods, without too many restrictions, which is a more reasonable rule. 
Table 3. Online Education Platform User Content Licensing Method

\begin{tabular}{|c|c|}
\hline Online education platform & Licensing method \\
\hline Udacity & Non-exclusive, free, permanent, irrevocable, commercial use \\
\hline Udemy & Non-exclusive \\
\hline Coursera & Non-exclusive, free, permanent, transferable \\
\hline edX & $\begin{array}{c}\text { Non-exclusive, free, permanent, transferable, licensable, irrevocable, commercial } \\
\text { use }\end{array}$ \\
\hline FutureLearn & Non-exclusive, free, permanent, reaciable, irrevocable \\
\hline Iversity & Non-exclusive \\
\hline Open2Study & $\begin{array}{c}\text { Non-exclusive, free, permanent, transferable, licensable, irrevocable, commercial } \\
\text { use }\end{array}$ \\
\hline FUN MOOC & Not agreed \\
\hline Novoed & Non-exclusive, free, permanent, transferable, reaciable, irrevocable \\
\hline Khan Academy & Non-exclusive, free, permanent, transferable, irrevocable, commercial use \\
\hline Baidu Education & Free, permanent, irrevocable, non-exclusive and full re-licensing \\
\hline Hujiang Net & Free, permanent, irrevocable, non-exclusive, and full re-licensing \\
\hline Netease Cloud Classroom & no agreement \\
\hline Tencent classroom & no agreement \\
\hline Academic education & no agreement \\
\hline New Oriental Online & no agreement \\
\hline $\begin{array}{l}\text { Learn and think online } \\
\text { school }\end{array}$ & no agreement \\
\hline Huatu Network School & no agreement \\
\hline Cross-test network school & no agreement \\
\hline School online & no agreement \\
\hline
\end{tabular}

\subsection{Protocol Mode Type}

Through the investigation of 12 online education platforms that have agreed on user content, namely Table 3 , there are two main ways to find an agreement between the platform and the user: (1) The user needs to click and choose accept or not accept the user content agreement provided by the platform. The next step can be performed (as shown in Figure 1), and if the user chooses not to accept the agreement content, the next step cannot be performed, which means, the registration cannot be performed, and the course service provided by the platform cannot be used; (2) the user does not need to select You can register by agreeing to the content of the agreement (as shown in Figure 2). At the same time, no matter what kind of agreement method is selected by the online education platform, it is stipulated in its agreement that once registered as a platform user, it means agreeing to the relevant terms of the user content made by the platform.

In addition, other online education platforms see the terms in the registration interface, but the terms provided by the platform are all hyperlink types, you need to click to jump to another interface to see the specific content of the terms, most Users often do not pay attention or ignore it directly, which is not conducive to users' knowledge of the relevant provisions of user content copyright. 
Table 4 Online education platform agreement signing method

\begin{tabular}{|c|c|c|c|c|}
\hline $\begin{array}{l}\text { Online education } \\
\text { platform }\end{array}$ & $\begin{array}{l}\text { agree before } \\
\text { register }\end{array}$ & $\begin{array}{l}\text { Terms can be seen in the } \\
\text { registration interface }\end{array}$ & $\begin{array}{l}\text { Click } \\
\text { contract }\end{array}$ & Remarks \\
\hline Udacity & $x$ & $\sqrt{ }$ & $\sqrt{ }$ & $\begin{array}{l}\text { Registration means } \\
\text { agreeing to the terms }\end{array}$ \\
\hline Udemy & $x$ & $\sqrt{ }$ & $\sqrt{ }$ & $\begin{array}{l}\text { Registration means } \\
\text { agreeing to the terms }\end{array}$ \\
\hline Coursera & $x$ & $x$ & $\sqrt{ }$ & $\begin{array}{l}\text { Registration means } \\
\text { agreeing to the terms }\end{array}$ \\
\hline edX & $\sqrt{ }$ & $\sqrt{ }$ & $\sqrt{ }$ & $\begin{array}{l}\text { Registration means } \\
\text { agreeing to the terms }\end{array}$ \\
\hline FutureLearn & $x$ & $\sqrt{ }$ & $\sqrt{ }$ & $\begin{array}{l}\text { Registration means } \\
\text { agreeing to the terms }\end{array}$ \\
\hline Iversity & $x$ & $\sqrt{ }$ & $\sqrt{ }$ & $\begin{array}{c}\text { Registration means } \\
\text { agreeing to the terms }\end{array}$ \\
\hline Open2Study & $\sqrt{ }$ & $\sqrt{ }$ & $\sqrt{ }$ & $\begin{array}{l}\text { Registration means } \\
\text { agreeing to the terms }\end{array}$ \\
\hline FUN MOOC & $\sqrt{ }$ & $\sqrt{ }$ & $\sqrt{ }$ & $\begin{array}{l}\text { Registration means } \\
\text { agreeing to the terms }\end{array}$ \\
\hline Novoed & $x$ & $\sqrt{ }$ & $\sqrt{ }$ & $\begin{array}{l}\text { Registration means } \\
\text { agreeing to the terms }\end{array}$ \\
\hline Khan Academy & $x$ & $\sqrt{ }$ & $\sqrt{ }$ & $\begin{array}{l}\text { Registration means } \\
\text { agreeing to the terms }\end{array}$ \\
\hline Baidu Education & $x$ & $\sqrt{ }$ & $\sqrt{ }$ & $\begin{array}{l}\text { Registration means } \\
\text { agreeing to the terms }\end{array}$ \\
\hline Hujiang Net & $x$ & $\sqrt{ }$ & $\sqrt{ }$ & $\begin{array}{l}\text { Registration means } \\
\text { agreeing to the terms }\end{array}$ \\
\hline
\end{tabular}

\section{There is a problem}

\subsection{User content copyright issues have not received attention}

From the survey of 20 online education platforms, there is no platform provider to form an independent clause on the copyright of user content. The relevant provisions of user content copyright are generally embedded in the terms of use policy or privacy policy, and even some terms. Whether or not there is legal effect remains to be discussed.

Through the comparison of Chinese and foreign online education platforms, it can also be found that most of the online education platforms in foreign countries have realized the importance of user content, and actively take measures to actively increase the relevant provisions of user content copyright in the terms signed with users, while most online education platforms in China do not realize the importance of user content. The legal awareness of users' online content generation is not strong, and there is no relevant regulation on the attribution and use of user content. The form and maturity of user content may be the reason for the improvement of the relevant regulations of the platform. The more mature the interactive link of the online education platform, the higher the value of the user content, the higher the importance of the corresponding platform to the user content, just as the online online education platform survey can be obtained, the platform developed from the online, such as Hujiang.com, etc. Compared with educational institutions that have emerged from the offline and then set up online platforms, such as New Oriental and Xuesi, there are more interactive links and user content, so their user content copyright awareness is stronger.

\subsection{The signing method violates the principle of equality}

When the online education platform signs the relevant agreement with the user for the copyright of the user content, there are three main problems:

(1) Format clauses ignore user rights

The relevant agreement on user content copyright should be the result of equal negotiation between the platform and the user. However, due to the network characteristics and technical characteristics, the agreement usually appears as a format clause. The user who is the opposite party of the contract can only accept the agreement completely. The right to use the online education platform greatly limits the user's right to choose ${ }^{[4]}$. The status between the platform service provider and the user is not equal. The user cannot choose the contract. Under the demand, although the user chooses to accept the format contract unconditionally, there is essentially no choice, otherwise the user can only give up online. The services provided by the education platform. The platform has 
mastered the initiative, and the rights of users are often ignored and violate the principle of equality.

The 20 online education platforms surveyed are required to register whether they agree to the platform's usage policy and privacy policy at the time of registration, regardless of whether the user has read the content of the user content agreement or understands and agrees to the terms of the agreement. As long as the user registers with the platform, they are deemed to have read and agreed to all the content of the clause, and due to the particularity of the network, the user cannot negotiate with the platform provider about the content and sign a separate copyright agreement, so if the user choose the online education service provided by the platform, they must accept the relevant provisions of the copyright of the user content specified by the platform, and the user's choice is denied.

(2) The platform service provider did not properly complete the reminder obligation

The relevant agreements signed by the 20 online education platforms and users are all in the form of hyperlinks. Users must actively click on various hyperlinks to see the relevant terms on another webpage, but the user does not click on the hyperlink. Influencing the progress of the program, even if the three online education platforms edX, Open2Study and FUN MOOC require the user to agree to the agreement, the next step of registration can be carried out. However, if you do not read the terms and directly choose to agree, you can continue the followup procedure, so you cannot ensure that the user has read and understood. Terms of copyright for user content. In addition, the relevant terms of the user content copyright are embedded in the large-scale terms of use or privacy terms, and the online education platform has not been clearly identified ${ }^{[5]}$, failing to properly perform the due reminder obligation or the reminder method. Obviously, the relevant provisions that result in the copyright of user content are easily ignored by users ${ }^{[6] .}$

\subsection{The agreement itself violates the principle of fairness}

Throughout the relevant provisions of 20 online education platforms and users' copyright agreement on user content, it can be found that most of the terms belong to the overlord clause, and the online education platform uses its terms of use and the status of the privacy policy maker to make use of its natural provisions. Advantages, reduce or even exempt one's own responsibility, and increase user obligations ${ }^{[7]}$. In addition to the Udemy and Iversity platforms, the Udemy and Iversity platforms only provide non-exclusive, non-exclusive user content licensing methods, and other platforms require permanent free irrevocable and reaciable rights to user content, edX. The Udacity, Open2Study, and Khan Academy platforms also stipulate that user content can be used commercially, and the terms also stipulate that the user is responsible for the uploaded content, while the platform enjoys the exemption clause, and the platform and the user's rights and obligations are completely different, in violation of the principle of fairness.

\subsection{User litigation rights difficulties}

The online education platform has not signed detailed regulations on copyright of users, and users lack a basis for rights protection. At the same time, online education users are in a weak position, and it is difficult to collect evidence through the information network for rights protection ${ }^{[8]}$. Taking Hujiang.com as an example, the Shanghai Jiang Legal Department has made it clear that strong copyright protection is a prerequisite for the development of online education. For this reason, Hujiang.com has also repeatedly defended the rights of the courses of the Shanghai River Network. Judicial activities actively cracked down on online piracy, and thus won the "2017 China Copyright Annual Most Influential Enterprise Award"; but even if Hujiang.com pays so much attention to copyright issues, Hujiang.com's user content copyright issue is still criticized. The relevant content posted by the user in the tribe is not protected by copyright, and the post on the Hujiang network platform that infringes the copyright of the user content is not processed in time. User content rights are difficult to defend, and online education platform has become a common problem.

\section{Countermeasures}

4.1 Improve user content copyright protection awareness

The particularity of user content has led to different levels of neglect of user content and its copyright issues, whether by legislators, platform providers or users. Although the continuous advancement of information technology and the Internet has accelerated the legislative process of online copyright in China, the laws and regulations related to online copyright have gradually become rich and mature, but the legislative work of online education user content is lagging behind, and the relevant provisions are not enough to solve the problem. In addition to the problem of content copyright, users often ignore the protection of the copyright of their own user content.

In this regard, legislators, users and platform providers should raise the awareness of copyright protection of user content. Legislators should actively improve relevant laws and regulations to comply with the trend of user content in the network era in the future, and improve users while protecting user content. The use efficiency of content: users should enhance the awareness of risk prevention on the basis of respecting the copyright of other 
users' content, and actively take measures to protect the copyright of their content from infringement, such as affirming copyright at the time of publication, actively defending rights when infringement, and adopting the first time Screenshots and other means to preserve the original evidence, etc. ${ }^{\text {9]; }}$ platform providers actively promote and positively guide, enhance user awareness of copyright protection, alert users to the typical case, and proactively apply appropriate copyright to users with more influential user content.

\subsection{Improve user content copyright regulations}

On one hand, although the copyright law regulates the behavior of network users and protects legitimate user content, user content as a new thing inevitably breaks through the scope of the existing copyright law ${ }^{[10]}$, Chinese statute law and judicial interpretation where are relatively few provisions on user content. Legislators do not specifically stipulate relevant content at the beginning of the law. It is recommended to standardize and refine the user content system in China's Civil Code, especially for online trading platforms. The provider's obligation of this special subject is regulated, the targeted protection of the legitimate rights and interests of users is strengthened, the legal gap in the copyright of user content is filled, and the user content system of China is improved ${ }^{[11]}$. On the other hand, most online education platforms in China have not made relevant provisions on user content, which is likely to cause copyright infringement of user content. The platform should actively sign a reasonable and effective user content copyright agreement with users to standardize the platform and user content.

\subsection{Reasonable regulatory format clause}

First of all, the online education platform should balance the rights of the platform and users when formulating user content copyright agreements, avoid the current status of monopoly of user content copyrights on the platform, and legally retain the validity of the provisions of the platform to reduce or exempt self-responsibility, terminate the platform responsibility, increase the platform rights, and weaken the user's rights. The user must make reasonable prompts. For the clause to reduce the user's rights, at least three months notice should be given to give the user consideration of the terms or provide sufficient time for consultation with the platform. In the format clause, the content of the user content copyright is detailed, and the user is clearly informed of the rights to the user content. The information can be refined into a form, allowing the user to choose which rights to transfer to the platform, and change the previous binding. At the same time, the online education platform should clarify the copyright owner of the user's user content. The platform and other person should obtain the authorization of the user for any form of commercial use. The authorization method can refer to the relevant content of the knowledge sharing agreement, and the user can "retain the part". Rights, providing a variety of alternative forms of authorization and combinations of terms, enabling selective authorization, such as the use of "signature-non-commercial use-same sharing" model ${ }^{[12]}$

\subsection{Increase the obligations of the platform provider}

Terms of use and privacy policies are unilaterally developed by online education platform providers, and they tend to plunder the rights of user content, but lack the corresponding user rights and protection content ${ }^{[13]}$. Therefore, it is possible to increase the risk of the agreement by forcibly increasing the obligations of the platform provider, and change the unfair state that the previous platform provider imposes in the clause that it does not assume any responsibility for the user content.

First, (1) guarantee the corresponding rights of the user's authorship and property rights; (2) copyright review. User content will inevitably involve the rights of third-party authors. The platform provider shall assist the user in obtaining the copyright license of the third party or auditing whether the user content is infringing; (3) The user has the right to modify or revoke the agreement. For example, in 1997 the EU Directive on the Protection of Consumer Rights in Remote Sales Contracts clearly states that before the conclusion of a remote contract, the consumer must obtain information about the main terms of the contract and the consumer is entitled to within 7 working days. The right to revoke the contract without liability for breach of contract, the platform provider should also give the user the right to modify or revoke the user content copyright agreement. (4) The platform provider has the duty of reminding. On the one hand, the online education platform should provide users or agents with an opportunity to review the copyright terms of user content in a significant way in the form of a notice that can be brought to the attention of ordinary people or in a prominent position; the platform should provide a reasonable review and conditions, such as reminding the user to pay attention to the terms and conditions in a striking font, especially the terms relating to how the user's content copyright is divided, exempted or restricted, should be reviewed by the user in a direct and obvious way, otherwise the user may claim that the relevant terms are invalid. On the other hand, the online education platform uses a specific form of explicit expression in the terms of the user interface to alert the user to the user ${ }^{[14]}$, in order to remind the user, for example, in the process of signing the agreement, the computer program design automatically appears the webpage ${ }^{[15]}$ of the terms of the agreement specifically invites users to understand the terms of exemption and 
limitation.

\section{Conclusion}

Online education as an emerging industry, its long-term good development is inseparable from online interaction with users. Online interactive links are the key content that must be added to online education in the future. The content of online education users is bound to increase sharply. Therefore, it is necessary to plan ahead for the Internet. At the same time, as the relevant laws, the copyright issue of online user content is included in the legal framework to regulate. The copyright law regulates the behavior of network users and protects legitimate user content, and the emerging new problems drive the revision of the copyright law, just as the emergence of online education user content copyright issues promotes the revision of the Copyright Law. When the law cannot solve the problem, a new law will come into being.

Suggested future works include developing legal protection of user-generated content, revising the Copyright Law,increasing the protection regulation for user-generated content,regulating the terms of users of online education platform, and enhancing users's awarenessof copyright.

\section{References}

[1] Juan Bai . (2016), "Copyright Management Analysis and Digital Copyright Protection in MOOC Development ",Library and Information Service S1,37-40.

[2] Lixin Yang . (2015), "The conditions of the network platform providers are not really joint responsibility and partial joint responsibility" , Law Science (Journal of Northwest University of Political Science and Law ,166-177.

[3]Dongmei Xiao ,Xiuwen Wu ,Fang Liu .(2015), “The Deconstruction of MOEP Phenomenon from the Perspective of Educational Resources Allocation ",Library,17-21.

[4] Tianhao Zhang . (2016),“ On the Effectiveness of Special Restrictive Clauses in Information Network Communication License Contracts ",Intellectual Property,63-67.

[5] Peng Zhao .(2016), "The Boundary of Private Review_—On the Administrative Responsibility of Online Trading Platform for User Content ",Tsinghua Law, 115-132.

[6] Xiao Si .(2018), "The setting of intellectual property attention obligations of network service providers ", Law Science (Journal of Northwest University of Political Science and Law), 78-88.

[7] Yuyu Yang.(2018), "Research on the Special Mechanism of Personal Information Protection-Taking the Personal Data Protection Law of Macao as a Sample ”,Library, 68-74.

[8] Qiuyue Li, Yuwen He.(2018), “Our Science Data Rights Protection Issues and Countermeasures—-Text Analysis Based on Sharing Policy" ,Library, 74-80.

[9] Kristofer Erickson.(2016), "User illusion: ideological construction of 'user-generated content'in the EC consultation on copyright Internet Policy Review[EB/OL],https://policyreview.info/articles/analysis/userillusion-ideological-construction-user-generated-content-ec-consultation.

[10]Shubao Liu , Aixia Wang .(2017), "Research on the Liability of Digital Library Users' Copyright Infringement from the Perspective of Civil Law ",Library,72-75.

[11] Zhiwen Liang.(2017) ,"The Copyright Regulation System of Network Service Providers ” , Law Science (Journal of Northwest University of Political Science and Law),100-108.

[12] Yan Xu , Zhang Aixia, Ma Sizhen.(2018), "The Intellectual Property Balance Mechanism in Science and Technology Reporting Service ”, Science and Technology Management Research 38(03),193-197.

[13]Xuxia Lin .(2012), “ On the Legal Regulation of the Agreement between Network Operators and Users ”[J]. Law Science (Journal of Northwest University of Political Science and Law) 30(5), 140-147.

[14] PK Yu. (2015),"The Right to Parody and User-Generated Content[EB/OL],https://www.law.berkeley.edu/files/Yu_Peter.

[15] LimingWang .(2016) ,"On the Key Issues of Internet Legislation ” [J]. Law Science (Journal of Northwest University of Political Science and Law),110-117. 